\title{
Exposure to glycols and their renal effects in motor servicing workers
}

\author{
J. Laitinen*, J. Liesivuori* and H. Savolainen ${ }^{\dagger}$ \\ * Regional Institute of Occupational Health, Kuopio, Finland, and \\ ${ }^{\dagger}$ Institute of Occupational Health Services, University of Lausanne, \\ Lausanne, Switzerland
}

\begin{abstract}
Ten car mechanics frequently exposed to glycol-based cooling liquids were followed during a workshift. Airborne ethylene and propylene glycol concentrations in the car mechanics' environment were measured. The car mechanics gave urıne samples after the workshift and their excretion of ethylene glycol, propylene glycol, oxalic acid, calcium and ammonia was analysed and compared to that of unexposed office workers. Urınary succinate dehydrogenase activity and glycosaminoglycans were also measured in both groups. Airborne ethylene and propylene glycol concentrations in the car mechanics' environment were neglıgible. Urinary ethylene glycol excretion in exposed workers was significantly higher than that in unexposed workers, but propylene glycol excretion was at the same level as in controls. In the exposed group, the excretion of the end metabolite of ethylene glycol, oxalic acid ( $47 \pm 11 \mathrm{mmo} / \mathrm{mol}$ creatinine, mean $\pm \mathrm{SD}, n=10)$ differed slightly from that of controls ( $36 \pm 14 \mathrm{mmol} / \mathrm{mol}$ creatinine, mean $\pm S D, n=10$ ). Urinary excretion of ammonia was higher among exposed workers than office workers. The excretion of calcium did not differ from that of controls. A marginally decreased urinary succinate dehydrogenase activity was found in the exposed men. The excretion of glycosaminoglycans was significantly lower in exposed workers. Therefore, it seems that ethylene glycol is absorbed by skın contact. The internal body burden is associated with oxaluria and increased ammonaagenesis typical of chronic acidosıs.
\end{abstract}

Occup. Med Vot 45, No. 5, pp 259-262, 1995

Engine coolants typically contain ethylene or propylene glycol as an anti-freeze. Their human and environmental toxicity is well known ${ }^{1}$. Chronic ethylene glycol exposure is associated with metabolic acidosis ${ }^{2}$. If the possibility of ethylene glycol dermal exposure is suspected, the glycol can be analysed in blood or urine samples ${ }^{3}$.

The metabolic end product of ethylene glycol is oxalic acid $^{4}$. It has considerable renal toxicity as it precipitates urinary calcium ${ }^{5}$ and inhibits cytochrome oxidase activity in renal mitochondria ${ }^{6}$. Both effects become clinically significant at moderate oxalic acid doses ${ }^{7}$.

The low vapour pressure of the glycols dissolved in water mixtures probably explains the fact that very little ethylene or propylene glycol has been found in air samples ${ }^{8}$. This does not exclude percutaneous absorption of the agents as the hands of the mechanics often come into contact with the spent coolants in their evacuations.

In this paper, we show that this seems to be the case and that exposure is associated with biochemical renal effects. This may necessitate better skin protection and a regular biological monitoring programme.

Correspondence and reprint requests to: J. Laitinen, Regional Institute of Occupational Health, PO Box 93, SF-70701 Kuopio, Finland.

\section{SUBJECTS AND METHODS}

Ten male car mechanics participated in this study. All participants benefitted from the obligatory employee occupational health programme of their respective companies and all were in habitual good health. They had 15 \pm 8 years of experience in their current occupation. They came from five different garages and the use of ethylene glycol was $540 \pm 400$ litres per garage per year (mean \pm SD). Our subjects either did not wear gloves at all or used leather ones when handling the coolant liquid.

The exposure of car mechanics to airborne ethylene and propylene glycol vapours was measured during a whole shift in the garages. Air samples were taken into silica tubes and desorption of the samples was performed using a mixture of isopropanol and water. Samples were analysed using a gas chromatograph equipped with a flame ionization detector ${ }^{8}$. Detection limits for airborne ethylene and propylene glycol during the whole workshift monitoring were $1.9 \mathrm{~cm}^{3} / \mathrm{m}^{3}$ and $3.2 \mathrm{~cm}^{3} / \mathrm{m}^{3}$, respectively, which are $4-6 \%$ of the current occupational exposure limit for ethylene glycol in Finland.

All participants gave urine samples after the workshift. The glycols in urine were analysed by a gas chromatographic technique using an electron capture detector? 
Their concentrations were corrected for the creatinine concentration determined by the alkaline picric acid method. Oxalic acid was analysed according to a modification of the method described by Sakai et al. ${ }^{10}$. The extraction liquid was modified and the extraction was repeated three times. The best extraction solution for oxalic acid was ethyl acetate. The samples were kept at room temperature during analysis, because oxalic acid can easily break down to carbon dioxide and formate. Calcium ${ }^{11}$, ammonia ${ }^{12}$, glycosaminoglycans $(G A G)^{13}$ and succinate dehydrogenase activity ${ }^{14}$ were analysed in the same samples. The car mechanics' patterns of excretion were compared to excretion in the ten age-matched male office workers serving as a control group.

The difference in the excretion patterns compared to the control group was tested statistically using a twotailed Student's $t$ test.

\section{RESULTS}

Ethylene glycol or propylene glycol vapours could not be detected in the air of the workers' breathing zones during the change of engine coolants, change of radiators or their repair, installation of new engine warming blocks, or during motor or car overhaul. Despite this, the average urinary ethylene glycol excretion of exposed workers was 3.8-fold higher than that of unexposed workers. Propylene glycol excretion was at the same level as that in the controls (Table 1). The exposure to ethylene glycol was particularly associated with major engine repair and change of engine warming blocks, while simple addition of coolant did not cause increased ethylene glycol excretion (Figure I). In group 1 , worker I performed four installations, worker 2 performed two installations and worker 3 performed only one installation of a new engine warming block (Figure 1). This shows that short exposure periods did not cause increased ethylene glycol excretion. On the other hand, the workers' urinary excretion of ethylene glycol was increased heavily after a longer exposure period during motor overhaul (group 2). Repair of radiators (group 3) and brake servicing group (group 4) also caused significantly increased excretion of ethylene glycol compared to

Table 1. Car mechanics' excretion pattern and renal effects of glycol compared to unexposed controls

\begin{tabular}{lccll}
\hline & $\begin{array}{c}\text { Exposed } \\
\text { workers } \\
(n=10)\end{array}$ & $\begin{array}{c}\text { Controls } \\
(n=10)\end{array}$ & Units \\
\hline 1.2-PG & $1.9 \pm 1.5$ & $2.3 \pm 1.4$ & $\mathrm{mmol} / \mathrm{mol}$ creatinine \\
EG & $7.3 \pm 4.7^{*}$ & $1.7 \pm 0.7$ & $\mathrm{mmol} / \mathrm{mol}$ creatinine \\
Oxalic acid & $47 \pm 11$ & $36 \pm 14$ & $\mathrm{mmol} / \mathrm{mol}$ creatinine \\
Ammonia & $3.4 \pm 1.2$ & $2.4 \pm 1.1$ & $\mathrm{~mol} / \mathrm{mol}$ creatinine \\
Calcium & $0.17 \pm 0.10$ & $0.27 \pm 0.12$ & $\mathrm{~mol} / \mathrm{mol}$ creatinine \\
SDH & $0.8 \pm 0.7$ & $1.5 \pm 0.9$ & $\mathrm{mmol} / \mathrm{min} \times$ mol creatinine \\
GAG & $3.1 \pm 1.0^{\circ}$ & $4.7 \pm 1.9$ & $9 / \mathrm{mol}$ creatinine \\
\hline
\end{tabular}

1,2-PG = propylene glycot, EG = ethylene glycol, $\mathrm{SDH}=$ succinate dehydrogenase activity, $G A G=$ gtycosaninoglycans

-Significantly different from controls, $P<0.05$
1. Inctllation of four new enpine warming blocka

2. Installation of two new entine warming blocks

3. Inrtallation of one new engine maming bloct

4 Motor overhaul

5. Motar overtheul

6. Repar, washing and test preasuring of aix radiatore

7. Repair of two rediators

8. Servicing of brakes and change of brake fluids

9. Adjurtment of brakes and chenge of engine warming bloct

10. Normal car overhad

Arerage urinary ethylene glycol excrotion in controle

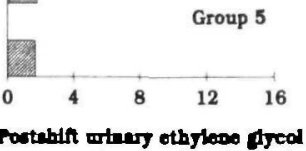

Pontabif utary ethylooe dyeal

Flgure 1. Servicing work associated with ethylene glycol exposure.

that of controls and the worker who did only a normal car overhall (group 5) (Figure 1).

In the exposed group, the excretion of the end metabolite of ethylene glycol, oxalic acid $(47 \pm 11 \mathrm{mmol} / \mathrm{mol}$ creatinine, mean $\pm \mathrm{SD}, n=10$ ) differed slightly from that in controls $(36 \pm 14 \mathrm{mmol} / \mathrm{mol}$ creatinine, mean \pm SD, $n=10$ (Table 1). Urinary excretion of ammonia was significantly higher among exposed workers compared with the excretion in office workers (Table 1). The excretion of glycosaminoglycans was significantly decreased among exposed workers. Marginally decreased urinary succinate activity and decreased excretion of calcium were found in the exposed men.

\section{DISCUSSION}

The vapour pressure of ethylene glycol is small, but it seems that ethylene glycol passes through the skin to a very significant extent if the hands are not protected. For these reasons, air monitoring in most cases does not show total exposure. A high airborne vapour concentration of ethylene glycol can hardly occur at any workplace, because the saturation vapour concentration for ethylene glycol is low compared with other solvents. The specific urinary analysis of ethylene glycol makes it possible to evaluate only total exposure to ethylene glycol. The excretion of oxalic acid could also be used for extra indication of exposure, but it is not specific enough in itself as oxalic acid is a constituent of normal urine as well.

The background levels of ethylene glycol could be caused by unspecified environmental exposure to chemicals. The most important routes of exposure to ethylene 
and propylene glycol for members of the general population are ingestion and dermal contact with products containing these compounds. Several products may possibly have caused the urinary background levels of propylene glycol, since propylene glycol is a solvent for various pharmaceutical, food and tobacco products. For example, some food colours and flavours contain propylene glycol as a solvent. Propylene glycol is used as an emollient in pharmaceutical and cosmetic creams, because it readily absorbs water ${ }^{15}$.

Propylene glycol may initially metabolize to methylglyoxal, which can cause significant toxic reactions in diabetics ${ }^{16}$ whereas it is not associated with kidney stone formation as the oxalic acid is ${ }^{17}$. However, none of our cases had had bouts of kidney stones. In an epidemiological study, no clear occupational aetiology was found for urolithiasis ${ }^{18}$, and the authors concluded that future studies should instead pay attention to genetic or dietary hypotheses.

Little is known of the physiological role of urinary proteoglycans although they have a role in the barrier functions of the nephron ${ }^{19}$ in preventing the precipitation of calcium salts ${ }^{20}$. The decreased excretion of proteoglycans may therefore prove to be an early indicator of metabolic effects of ethylene glycol metabolites in the kidney.

Kidneys are highly dependent on oxidative metabolism for energy ${ }^{21}$ and therefore tubular cells contain numerous mitochondria. Succinate dehydrogenase activity is associated with the mitochondrial respiratory chain, and its decreased activity could reflect the biochemical effects of oxalate in mitochondria ${ }^{6}$. Similar results have also been obtained in previous studies on silk-screen printing workers who are exposed to glycol ethers and their acetates ${ }^{20}$. It remains to be seen whether it has a role in the evaluation of clinical effects in occupational glycol exposure.

Urinary ammonia concentration typically increases in chronic metabolic acidosis ${ }^{22}$. It is doubtful whether this could be verified by blood $\mathrm{pH}$ analyses in the car mechanics while it could represent an adaptation mechanism at renal tubular level for excretion of the exogenous acid load ${ }^{23}$.

In total, 8.1 and 7.4 million litres of ethylene and propylene glycols, respectively, were imported to Finland during 1993. The major proportion of this ethylene glycol was used in coolant liquids according to the statistics of the Finnish custom service. The handling of spent coolant in quantities is a major problem everywhere. Apart from the economic value attached to its proper handling, it seems that exposed workers everywhere would merit specific monitoring efforts to avoid potential kidney problems. They should also be aware of the possibility that coolant components may penetrate the skin to a significant extent. Urinary ethylene glycol determinations should be included in the biological monitoring schemes for garage workers. Perhaps urinary oxalic acid concentration should be analysed in the medical aptitude examinations performed before employment in order to exclude workers with hyperoxaluria.

\section{ACKNOWLEDGEMENTS}

The authors are grateful to Ms N. Chavannes and Ms T. Turunen for their excellent technical assistance and to the Finnish Work Environment Fund for financial aid.

\section{REFERENCES}

1. Randall PM, Gavaskar AR. Evaluation of filtration and distillation methods for recycled automotive coolant. $\mathcal{J} \mathrm{A}$ ir Waste Mgmt Assoc 1993; 43: 463-8.

2. Kaiser $W$, Steinmauer $H-G$, Biesenbach $C$, Janko $O$, Zazgornik J. Chronische Ethylenglykolvergiftung. Disch Med Wochenschr 1993; 118: 622-6.

3. Blandford DE, Desjardins PR. A rapid method for measurement of ethylene glycol. Clin Biochem 1994; 27: 25-30.

4. Fraser AD, MacNeil W. Colorimetric and gas chromatographic procedures for glycolic acid in serum: the major toxic metabolite of ethylene glycol. Clin Toxicol 1993; 31: $397-405$.

5. Borsatti A. Calcium oxalate nephrolithiasis: defective oxalate transport. Kidney Int 1991; 39: 1283-98.

6. Bachmann E, Goldberg L. Reappraisal of the toxicology of ethylene glycol. III. Mitochondrial effects. Food Cosmet Toxicol 1971; 9: 39-55.

7. Gabov PA, Clay K, Sullivan JR, Lepoff R. Organic acids in ethylene glycol intoxication. Ann Intern Med 1986; 105: $16-20$.

8. Tucker SP, Deye GJ. A sampling and analytical method for ethylene glycol. Anal Lett 1981; 14: 959-76.

9. Goën TH, Hubner B, Schaller KH, Angerer J. Analytical procedure for the determination of 1,2-propylene glycol and diethylene glycol in blood and urine. Abstract, International Symposium on Health Hazard of Glycol Ethers. Nancy-Pont-a-Mousson, 19-21 April 1994, p. 123.

10. Sakai T, Araki T, Masuyama Y. Determination of urinary alkoxyacetic acids by a rapid and simple method for biological monitoring of workers exposed to glycol ethers and their acetates. Int Arch Occup Environ Health 1993; 64: 495-8.

11. Gindler EM, King JD. Rapid colorimetric determination of calcium in biological fluids with methymol blue. $A m \mathcal{F}$ Clin Pathol 1972; 53: 376-82.

12. Ratnaike RN, Buttery JE, Hoffman S. Blood ammonia measurement using a simple refractometer. $\mathcal{F}$ Clin $\mathrm{Chem}$ Biochem 1984; 22: 105-8.

13. Thuy LP, Nyhan WL. A new quantitative assay for glycosaminoglycans. Clin Chim Acta 1992; 212: 17-26.

14. Lim R, Hsu L-W. Studies on brain-specific membrane proteins. Biochim Biophys Acta 1971; 249: 569-82.

15. Technical report for ethylene glycol and propylene glycol. Washington DC: US Department of Health \& Human Services, Public Health Service, Agency for Toxic Substances and Disease Registry, 29 November 1993.

16. Thornalley PJ. Methylglyoxal, glyoxalases and the development of diabetic complications. Amino Acids 1994; 6: 14-23.

17. Coe FL, Parks JH, Asplin JR. The pathogenesis and treatment of kidney stones. N Engl $\mathcal{J}$ Med 1992; 327: $1141-52$.

18. Thun MT, Schober S. Urolithiasis in Tennessee: an occupational window into a regional problem. $A m \mathcal{J} P u b l i c$ Health 1991; 81: 587-91.

19. Savolainen H. A sensitive method for analysis of urinary proteoglycans. Biochem Int 1992; 28: 475-9.

20. Laitinen J, Liesivuori J, Savolainen H. Urinary biochemistry in occupational exposure to glycol ethers. Chemosphere 1994; 29(4): 781-7.

21. Schlichtig R, Kramer DJ, Boston JR, Pinsky MR. Renal 
$\mathrm{O}_{i}$ consumption during progressive hemorrhage. $\mathcal{F} A p p l$ Physiol 1991; 70: 1957-62.

22. Golden MHN, Jahoor P, Jackson AA. Glutamine production and its contribution to urinary ammonia in normal man. Clin Sci 1982; 62: 299-305.

23. Garlisle EJF, Donnelly SM, Vasuvattakul S et al. Gluesniffing and distal renal tubular acidosis: sticking to the facts. $\mathcal{F}$ Am Soc Nephrol 1991; 1: 1019-27. 